(Revised to Apri1 3, 1934)

\title{
AUTOINOBILE ENGINE GRAPHITED LUBRICANTS
}

The Bureau of Standards receives numerous inquiries regarding various trademarked lubricants containing graphite for use either in the crankcase of automobile engines or as an upper cylinder lubricant. In order to facilitate the answering of these inquiries, this letter circular has been prepared as a general analysis of the available inform tion on automobile engine graphited lubricants.

Viscosity is the most important property of a crankcase oil. In any given engine operating under "normal" conditions, the bearing friction is determined by the oil viscosity at the operrting temperature, speed, and load. The lower the viscosity, the lower will be the friction under normal operating conditions. If the viscosity is lowered too much, however, inadequate lubrication mill result and bearing failure may occur. No evidence has been obtained that the use of grabhite in the oil will lower friction in engine bearings when the engine is operated under full film conditions. When graphite is. added to the mineral oil in the form of a preparation of low viscosity, as is often done, the viscosity of the oil after mixing is lower than the viscosity of the original oil. If this is the case, the normal bearing friction will be reduced only on account of the lomer oil viscosity.

Under operating conditions more severe than those normally encountered in service, viscosity is not the only factor determining bering friction and many substances are known which when blended with oil will materially lower the friction, even though the viscosity of the blend is the same as that of the original oil. Under these severe operating conditions a slight lowering in bearing friction in automotive engines may result from the use of graphite.

Any effect of graphite on the friction between the piston rings and the cylirders is more uncertain. A reduction in friction might be caused either by the graphite or by a lorering of oil viscosity. It is knomn that graphite tends to fill up the pores of cast iron surfaces and to adhere very tonaciously. This may result in a someWhat smoother surface and may produce a slight lowering in the friction. The result of any lowering of oil vis- 
cosity due to blending with the "graphited preparation will lower the friction to an extent dependent upon the change in viscosity on blending.

Use of a lucricated gasoline conteining graphite appears to be of little bcnefit in general while the engine is operating under no rmal conditions, for in most cases more luoricant than is necessary for adequate lubrication ts past the piston rings. The use of an upper cylinder lubricant at times may be of somo assistance as a temporary remedy in reducing the tendency of valves to stick. During engine starfing under conditions where the cylindor alls, have lit tle lubricant on them, the use of a lubricated gasol.ine may be of some benefit in tending to raduce the rear on the piston rings and cylinders. During the process of creaking.in an engine, use of a lubricated gasoline apoears to have real value although the Bursau has no information as to whether the presence of graphita is of any material assistance or not.

Graphited lubricants have frequently bean condemned on account of their abrasive properties, but this seems to be largely, attributable to impurities in the graphite. It is reported that it is now possible to obtain graphite free from these abrasive matorials and that there is little tendency to cause increased wear. This is probably true as regrads cylinder walls, where loss of metal may be reduced by a protective coeting of graphite. There is evidence thot some "lapping" action occurs in berrings which are new or tight. Whether this action continues or is objectionable after the bearings are properly run in, is not definitely known.

One of the characteristics of graphited lubricents is that the graphite tends to settle out in service if the mineral acid content of the oil increases with use. In this case, any effectiveness due to the presence of graphite in the oil is largely lost. On the other hand, due to the small amount of graphite present in the oil, it would not be expected that any settling out would normally result in damage to the engine.

No appraciable increase in engine horsepomer or in maximum car speed would be expected as the result of using graphite in an engine in good mechanical condition, unless the blending with the graphited preparation proauced a decrease in viscosity. Oil consumption with a well-designed engine in good mechanical condition rould tend to increase in those cases where there is a lowering in viscosity. Gasoline consumption should not. be noticeably different on using a graphited lubricont unless the croburetor setting is changed to give a leaner mixture, 
an effect independent of the use of the graphited lubricant. With a car which is not in good mechanical condition, deposition of graphite on the cylindar walls may in some cases result in a bettor seating of the piston rings against the cylinder walls, and thereby increase the horsepower and car speed, and decrease the oil consumption. 

